\title{
TECNOLOGIAS DIGITAIS E A APRENDIZAGEM: PERSPECTIVAS PARA EMERGÊNCIA DE ZONAS DE DESENVOLVIMENTO PROXIMAL
}

\author{
Juliana Silva Arruda, UFC-CE, julianarruda24@gmail.com \\ José Aires de Castro Filho, UFC-Virtual, aires@ virtual.ufc.br
}

Resumo: Analisa como os recursos digitais, utilizados em atividades realizadas com o uso das tecnologias digitais, podem fazer emergir Zonas de Desenvolvimento Proximal (ZDP) em grupos de dois ou mais aprendentes. Foi utilizada a metodologia qualitativa, com caráter interpretativo, através da observação participante, com análise microgenética, e, como instrumentos de coleta de dados: vídeos e diários de campo. As atividades planejadas envolveram disciplinas curriculares, o uso do computador e alguns recursos da Internet. Os resultados foram analisados de acordo com categorias, que foram verificadas a partir da unidade de análise: o suporte de tecnologia, destacando momentos que os recursos, aliados à interação, promovem a emergência de ZDP, acarretando aprendizagem e promovendo posturas de autoria desses aprendentes.

Palavras-chave: Tecnologias. Interação. Zonas de Desenvolvimento Proximal.

\section{Digital technologies and learning: perspectives for emergency of proximal development zones}

\begin{abstract}
Analyzes how digital resources, used in activities carried out with the use of digital technologies, can lead to the emergence of Proximal Development Zones in groups of two or more learners. The qualitative methodology was used, with an interpretive character, through participant observation, with microgenetic analysis, and as instruments of data collection: videos and field diaries. The planned activities involved curricular subjects, computer use and some Internet resources. The results were analyzed according to categories, which were verified from the unit of analysis: the support of technology, discounting moments that resources, allied to the interaction, promote the emergence of ZPD, entailing learning and promoting positions of authorship of these learners.
\end{abstract}

Keywords: Technologies. Interaction. Zones of Proximal Development.

\section{INTRODUÇÃO}

A sociedade brasileira vivencia um período de imersão tecnológica. Bonilla (2012) considera que há uma integração entre a tecnologia e a Educação. Martins et al. (2018) complementam que através da internet os trabalhos e pesquisas dos alunos podem ser compartilhados e divulgados de forma instantânea na rede, facilitando a interação.

Modernos recursos tecnológicos são desenvolvidos a cada dia, e a integração entre tecnologia e a educação se torna cada vez mais rotineira. Com isso, surgiu a necessidade de pesquisar aspectos do desempenho em sala de aula, o desenrolar das habilidades, a motivação e a cognição individual e em grupo (Resta; Laferrière, 2007).

A aquisição do letramento digital e o acesso às Tecnologias de Informação e Comunicação (TIC) proporcionam habilidades ao aprendente para processar, usar e transformar a informação, proporcionado por meio da conectividade, um aspecto básico para a construção da inclusão digital. Castells (1999), procurando entender como se dá esse processo, estabelece uma relação entre tecnologia e sociedade, considerando que esta última se desenvolve a partir de um sistema complexo de interação de avanço da ciência, transformações tecnológicas e atuação social. 
A inserção das tecnologias no contexto educacional constitui tema de interesse de pesquisadores como David (2010) e Meira e Lerman (2009), que realizaram investigações sobre o uso de recursos digitais na aprendizagem dos educandos. Na descrição teórica deste estudo, as investigações, bem como o construto teórico desses autores serão detalhados e relacionados às considerações, críticas e à ampliação da contextualização da Zona de Desenvolvimento Proximal (ZDP), compreendida aqui como o possível caminho do desenvolvimento (Vygotsky, 1994).

Considerando-se que o momento atual é cercado de informações quase instantâneas, principalmente devido à Internet, é adequado promover um incentivo ao estudo e à análise dos conteúdos divulgados, para que não ocorra apenas a disseminação indiscriminada, mas que esse processamento possa ser pensado, refletido e criticado. $\mathrm{O}$ interesse do presente estudo está focado na compreensão dos processos de aprendizagem mediada pela tecnologia e originou-se da seguinte questão: Como as atividades envolvendo o uso de recursos digitais favorecem a aprendizagem por meio da emergência de ZDP entre alunos do Ensino Fundamental de uma escola pública?

Partindo-se dessa problemática, define-se o objetivo geral deste estudo, que é investigar a emergência de ZDP dos educandos do Ensino Fundamental quando realizam atividades interativas com suporte de tecnologias digitais. Como objetivos específicos, propõem-se: 1) definir parâmetros identificadores da emergência de ZDP; 2) descrever as características do contexto no qual emergem as ZDP; e 3) identificar formas de se utilizar recursos digitais que possibilitem a emergência de ZDP.

Esta pesquisa pretende trazer benefícios e subsídios para facilitar a aprendizagem, utilizando as tecnologias como recurso nesse processo. Justifica-se o estudo considerando-se que as tecnologias, a cada dia, se apresentam como uma realidade das escolas brasileiras; no entanto, muitas vezes se desconhecem o seu verdadeiro potencial e a intensidade de suas contribuições para a aprendizagem dos alunos. Complementa-se a isso a busca pelo entendimento e a análise de recursos que podem auxiliar os processos educacionais, e facilitar a metodologia docente. Isso porque os docentes, pela falta de tempo ou de entendimento, não vislumbram o poder e as contribuições que a utilização desses recursos pode trazer na sua formação enquanto profissional da área da Educação, bem como na constituição de novos conhecimentos pelos aprendentes.

\section{REFERENCIAL TEÓRICO}

\subsection{A aprendizagem numa visão sócio-histórica}

Neste estudo, a aprendizagem tem um sentido dinâmico, haja vista a função de transformar e modificar o sujeito, tanto no aspecto cognitivo quanto no emocional, envolvendo o homem em sua totalidade. Alinha-se com a proposta sócio-histórica, que compreende a aprendizagem como resultado de uma construção social, fruto não apenas de uma trajetória individual, mas da inserção do indivíduo em um ambiente cultural e no processo histórico. Essa proposta tem L. S. Vygotsky como principal expoente.

Vygotsky (1994) considera a aprendizagem num contexto histórico-social, não necessariamente estudando o passado, mas no âmbito de seu desenvolvimento, segundo sua dinamicidade e suas transformações. Seus estudos não se baseiam apenas na objetivação da resposta, ou seja, no resultado, mas no caminhar desse processo de resolução, isto é, no processo de seu desenvolvimento. Analisando-se de maneira mais específica de que forma ocorre a aprendizagem, enfatizam-se as relações sociais como fator essencial (Meira; Spinillo, 2006). 
Para entender a complexa relação entre aprendizagem e desenvolvimento, Vygotsky (1994) considera dois aspectos: a relação geral entre ambos e os fatores específicos dessa relação, quando a criança chega à fase escolar. Consideração importante é que a aprendizagem se inicia bem antes da vida escolar; assim, muitos conteúdos vistos na escola já foram antes vivenciados. Entende-se que há interação entre aprendizagem com desenvolvimento desde os primeiros dias de vida do ser humano.

A aprendizagem afeta o desenvolvimento, ou seja, ambos se constituem de maneira relacional. O relacionamento do sujeito com a cultura traz o desenvolvimento, que, por sua vez, contribui para a formação da aprendizagem, e, posteriormente, acarreta um futuro desenvolvimento. Há, portanto, uma relação dialética entre desenvolvimento e aprendizagem, pois um complementa o outro (Meira; Spinillo, 2006).

Vygotsky (1994) formulou o conceito de ZDP para facilitar a compreensão da relação entre aprendizagem e desenvolvimento. No próximo tópico, as diferentes definições de ZDP serão discutidas, bem como suas ampliações.

\subsection{Zona de Desenvolvimento Proximal à luz de diferentes olhares}

Quando a criança aprende os primeiros nomes dos objetos, já começa sua aprendizagem de conteúdos escolares. Como os conhecimentos escolares são fonte geradora de novos desenvolvimentos, para tentar compreendê-los, Vygotsky (1994) propõe a Zona de Desenvolvimento Proximal, uma nova concepção imprescindível para o entendimento da aprendizagem educacional.

Sabe-se que a definição de ZDP vai muito além da esfera educacional, sendo uma emergência do conhecimento que é constituído e que não apresenta especificidade, expressando as interações humanas, possibilitando o processo de desenvolvimento de maneira dinâmica, fluida e indeterminada. A ZDP não se restringe ao contexto de educação formal, mas faz parte de todo o processo de constituição cultural possível entre as pessoas, emergindo em qualquer lugar em que as interações ocorrem.

A primeira formulação do conceito de ZDP propunha uma relação entre a distância do Nível de Desenvolvimento Real (NDR), ou seja, o que a criança já consegue realizar sozinha, e o Nível de Desenvolvimento Proximal (NDP), que é aquilo que a criança não consegue realizar sozinha, mas tem o potencial para tanto, pois, com a ajuda de alguém mais experiente, consegue fazê-lo (Vygotsky, 1994). Afirma ainda que aquilo que a criança consegue realizar com a ajuda de alguém mais experiente, mais tarde poderá realizar sozinha. Assim, a ZDP indica a possível trajetória do desenvolvimento, apontando caminhos pelos quais a criança pode evoluir.

A visão e a conceituação original que Vygotsky fornece para ZDP são caracterizadas por um processo estático, medido basicamente por um espaço entre o que a criança consegue realizar com autonomia e o que ela consegue fazer com assistência. Assim sendo, o que hoje ela não consegue realizar sozinha, mas o faz com ajuda (ZDP), posteriormente se caracterizará em NDR.

Meira e Lerman (2009) definem essa primeira formulação como restrita, haja vista que considera somente o desenvolvimento particular das funções psicológicas e a limita um meio físico fechado, que deve ser alcançado pelo educador, para que a aprendizagem venha a ocorrer. Compreende-se, então, a aprendizagem como um sistema dinâmico, com base no conceito da ZDP, desenvolvendo-se não a partir de um conhecimento predefinido, mas, de forma relacional, entre aprendentes-professor e aprendentes-pares.

Neste estudo, considera-se a ZDP na sua diversidade, acreditando-se não haver uma única ZDP. O que há, na verdade, são várias zonas, em cada campo de conhecimento, mediadas pelos educadores, pelos pares e pela família. Não há uma única ZDP, 
semelhante para todos os educandos, mas várias zonas construídas, ampliadas e repletas de expressões, sendo assim, são geradas diferentes e variadas ZDP, considerando-se que o efeito emergido em um aprendente é diferente dos seus pares, haja vista a individualidade, os conhecimentos anteriores e a história de vida (Oliveira, 2014). Dessa forma, a visão ampliada da ZDP abordada no estudo é considerada a partir dos conceitos e formulações de Meira e Lerman (2009), caracterizando-a como espaço semiótico construído durante as atividades, nas quais os pares, professores ou outros recursos propiciam uma aprendizagem. Dessa forma, não pode ser definida como preexistente, não é algo concreto, ou uma caixa fechada, e sim um espaço simbólico de interação em que a aprendizagem acarreta o desenvolvimento, sendo várias formas de interação no ambiente educacional que levam ao sucesso dos processos de ensino e aprendizagem.

\subsection{Estudos empíricos: tecnologia e visão sócio-histórica}

Com a globalização das informações, na atualidade, temas como compartilhamento e relações políticas e sociais surgem cada dia com mais frequência na sociedade. Não há mais limites espaciais para que diferentes realidades e contextos se cruzem e troquem informações. E é nesse universo que o tema interação torna-se cada dia mais visível, maximizando suas áreas de investigação e interesse, e envolvendo diferentes campos de pesquisa, como Educação, Psicologia e Linguística.

$\mathrm{Na}$ busca do entendimento desse conceito, por diferentes campos de pesquisa, o termo interação acaba sendo utilizado de maneira confusa, sendo, portanto, necessário considerar esse conceito com precisão, e compreender que ele precede o avanço das TIC. Segundo Resta e Laferrière (2007) todo dia novos recursos tecnológicos são desenvolvidos. Estudos, baseados em teorias sócio construtivistas, demonstram necessidade no envolvimento de ambientes educacionais interativos.

Há diferentes e variadas maneiras de ampliar novas metodologias utilizando sistemas uteis para melhor entendimento, envolvendo projetos de design através do uso da internet, usando os recursos computacionais na sala de aula com o apoio das atividades dividia em grupos. Cabe considerar que os campos de uso das TIC devem ser estudados e analisados cuidadosamente, objetivando delimitar como os recursos podem ser inseridos em contextos sociais reais, como a sala de aula (Nardi, 1996).

Segundo Colaço (2004), os fatores linguísticos estão associados às ações sociais e têm como origem as práticas de diálogos, que se efetivam na interação, apresentando atuações mediadoras nesse processo. Importa considerar a interação social, pois ela representa a base da constituição do sujeito em sociedade, que utiliza a linguagem como recurso dessa mediação. Representa-se a interação a partir dos estudos de Colaço (2001), que compreende a interação não apenas nas relações sujeito-sujeito(s), mas também como um processo básico do sujeito como ser social e historicamente constituído por ele próprio, no âmago dos conteúdos que são mediados pelas interações sociais, e na troca nessas relações, originando condições de emergência de ZDP.

Os estudos de Luckin et al. (2005) apontam a importância da aprendizagem de conteúdos específicos, utilizando como foco a aplicação educacional das tecnologias móveis. Consideram o processo de aprendizagem a partir da implementação de recursos, que podem ser inseridos de diferentes maneiras, mas sempre com o cuidado de promover e apoiar vários tipos de mediação, inclusive as relações entre educador e educando.

A influência dos avanços da tecnologia é fortemente dependente das especificidades da cultura educacional. A imersão tecnológica cada dia mais traz novas possibilidades de acessibilidade: sem fio, móvel e ubíqua (define-se pela onipresença da 
tecnologia no cotidiano contemporâneo), e oferece aos aprendentes a chance de relacionar suas vivências em vários contextos.

\section{MATERIAIS E MÉTODOS}

A metodologia tem abordagem de natureza qualitativa, considerando-se que as observações e as estratégias utilizadas pelos sujeitos serão analisadas e interpretadas. Bogdan e Biklen (1994) definem o estudo qualitativo como rigoroso e sistêmico, considerando ainda que, por meio deste, as informações coletadas têm como características detalhes sutis e específicos, e que, por essa razão, proporcionam melhor compreensão dos processos educacionais e psicológicos da aprendizagem.

Meira (1994) considera que a análise qualitativa de processos que consideram a cognição e a aprendizagem se torna complexa, pois envolve aspectos cognitivos, mudanças sensíveis e breves de gestos e comunicações. Existindo duas formas de análise que podem ser usadas para instrumentalizar a coleta e análise dos dados nas investigações relacionadas aos processos cognitivos e emocionais, a saber: a microgenética, que envolve um rebuscamento minucioso das trocas entre os sujeitos e as circunstâncias; e a videografia, que se caracteriza pela filmagem das situações, e é um suporte de registro para a análise microgenética. Ambas formas de análise são usadas nesse estudo.

Um dos pioneiros dos estudos microgenéticos, Vygotsky (1994) diz que em alguns curtos espaços de tempo podem ser desenvolvidos processos psicológicos. Essa análise se caracteriza pela assistência minuciosa do processo, fornecendo detalhes das atitudes individuais e grupais em um curto período, em sessões mínimas, com ações bem definidas e que promovem a interação, em condições espontâneas (Wertsch, 1985).

A presente investigação foi desenvolvida no contexto do projeto EDigital, que contou com a parceria do Grupo de Pesquisa da Universidade Federal do Ceará-UFC e a Companhia Energética do Ceará-COELCE. Seu objetivo principal é desenvolver competências através da formação da comunidade escolar, para a inclusão e o uso das tecnologias digitais na Educação.

O EDigital foi iniciado em 2013, com três segmentos de formação, que aliam a tecnologia à Educação: formação de professores, formação de alunos monitores e desenvolvimento de projetos que envolvem a sustentabilidade. A formação dos educadores foca na apropriação tecnológica, que se caracteriza pelo processo de apresentação dos recursos digitais. A formação de alunos monitores é caracterizada pela inclusão digital do educando, que entra no projeto de forma voluntária.

Para o desenvolvimento do estudo, não foi delimitado um número máximo de participantes. No entanto, houve número mínimo de dois, por grupo de alunos monitores. A escolha dos participantes contemplou alunos monitores do $6^{0}$ ao $9^{\circ}$ ano da escola, já que já estavam participando do processo de formação de alunos monitores. Tendo acesso aos recursos digitais, apresentaram mais facilidade de lidar com a tecnologia aliada ao cotidiano pedagógico. Os temas e assuntos considerados na produção dos vídeos dos alunos foram constituídos a partir de uma aula de campo pelos arredores da escola, apresentando como objetivo a tomada de consciência e o papel de cada um na sociedade, sendo relacionados ao que vinha sendo desenvolvido nas aulas de formação.

Os dados foram coletados pela pesquisadora, conforme detalhado a seguir: 1) Observação: acompanhamento do diálogo, gestos, das atitudes e interações entre os aprendentes; 2) Caderno de registro: descrição das observações, de forma detalhada e minuciosa, considerando as interações; 3) Entrevistas: foram realizadas e gravadas entrevistas com pequenos grupos, bem curtas, e gravadas; 4) Grupo do Facebook: buscouse observar a interação, bem como a mudança de opiniões e formação de novos, através 
da interação; e 5) Vídeos e fotografias: na análise microgenética, os registros fotográficos e os vídeos foram essenciais, fornecendo todas as atividades, e o que não foi possível observar, e complementam os demais recursos. Além de auxiliar na interpretação dos resultados, dão a chance de torná-los públicos.

\section{RESULTADOS}

Os resultados deste estudo são demonstrados tendo como base as categorias que foram acordadas na análise dos dados, partindo dos aportes teóricos sobre a ZDP. Importa considerar que essas categorias não se encontram isoladas, apesar de alguns aspectos semelhantes nos seus conceitos. Em seguida, será apresentada a unidade de análise, bem como cada categoria de análise e sua relevância para a pesquisa.

\subsection{Suporte da tecnologia}

As atividades desenvolvidas nesse estudo envolveram o suporte da tecnologia e foram planejadas de forma a serem desafiadoras e sensíveis à assistência da pesquisadora e dos pares, envolvendo os conhecimentos e os assuntos estudados pelos alunos. Essa unidade de análise envolve o desenvolvimento de espaços semióticos de aprendizagem, com o uso das tecnologias digitais como recurso. Sendo as situações determinadas pelo contexto adequado, a tecnologia pode propiciar um ambiente desafiador e fomentador de ZDP. E é através desse contexto formado por um conjunto de elementos interrelacionados de recursos, pessoas e os objetos, que emergem as ZDP.

Em seguida, as categorias do estudo serão analisadas, detalhadas e exemplificadas, a partir dessa unidade de análise, que forneceu o suporte necessário para o desenvolvimento de muitas das atividades e exemplos, além de desencadear diálogos e interações entre os aprendentes.

\subsubsection{Interação entre pares}

Considera-se como interação entre pares quando se estabelecem nas entrelinhas conversações e diálogos estabelecidos entre os alunos, demonstrando a ZDP como um espaço dinâmico. Também quando dois alunos ou mais conversam entre si sobre um tema acerca do qual antes não tinham entendimento, e, a partir do diálogo, negociam uma definição para esse conceito até então desconhecido. As atividades foram intermediadas pelo suporte da tecnologia, e como indicadores dessa unidade de análise tem-se a exibição e produção de vídeos, pesquisas pela internet, construção de textos e slides coletivos, que desencadearam as discussões entre os alunos.

Uma situação que exemplifica essa facilitação do uso da linguagem, nesse momento, a linguagem escrita, ocorreu no momento em que foi sugerido à turma que postasse comentários sobre os temas vistos na formação no Facebook, e eles, além de comentar, criaram imagens sugestivas de sustentabilidade, dando ideias e incentivando os pares. Quando o aluno M postou uma figura de um regador reciclado na rede social, o aluno $\mathrm{R}$ pesquisou o que ele poderia criar. Então, disse que queria fazer um gerador de energia utilizando água sanitária. Outros alunos sugeriram estabelecer oficinas de material reciclado na escola, corroborando que a imagem postada pelo colega, utilizando a tecnologia como recurso, facilitou R na busca de outras ações sustentáveis.

Outro momento em que se evidenciou a interação entre pares foi durante a aula de campo. Os alunos foram distribuídos em grupos, e resolveram formar nomes que os identificassem, durante a conversação, percebeu-se que eles procuraram negociar entre 
si, demonstrando interação. Depois de decididos os nomes, recorreram aos recursos da tecnologia para produzir as logomarcas, e mais uma vez divulgaram o compartilhamento de sua identificação na página da rede social, fomentando discussões, estabelecendo um ambiente dinâmico e interação dos aprendentes. Na Figura 1, é mostrada a logomarca de um dos grupos.

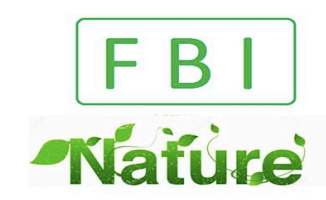

Fundação Bio Inteligente

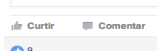

Figura 1 - Logomarca idealizada por um dos grupos no Facebook Fonte: Dados da pesquisa.

Outro aspecto a ser analisado na produção do slogan do grupo, que demonstra uma facilitação na aprendizagem dos conteúdos propostos, diz respeito ao fato de o nome da turma estar diretamente relacionado aos temas estudados durante a formação. Ressaltase, ainda, que não foi apresentada pela pesquisadora nenhuma sugestão; os aprendentes relacionaram sua identificação ao que tinha sido visto, conseguindo expressar o que haviam conversado, como a imagem das plantas relacionada a sustentabilidade.

O suporte da tecnologia facilitou a realização das atividades em grupo, em que os membros trabalham de maneira conjunta, utilizando o computador como recurso e elegendo uma meta comum. Pode-se perceber essa facilitação nas pesquisas em sites de busca, em que os alunos ampliaram a visão que tinham dos conceitos, na elaboração de textos colaborativos, conseguindo produzi-los utilizando o editor, além da produção de vídeos, em que os aprendentes puderam interagir entre os pares, discutir e formar um ambiente semiótico fomentador de conhecimento.

\subsubsection{Interação com alguém mais experiente}

Caracteriza-se a discussão com alguém mais experiente quando é estabelecido um diálogo com um ou mais alunos, e a partir dessa conversação o participante que ainda não conseguia entender um conceito passa a compreendê-lo. Outro aspecto importante da ZDP é que ela também se relaciona com o desenvolvimento de uma compreensão conjunta sobre algo, ou seja, duas ou mais pessoas que podiam ter concepções diferentes, começam através de uma conversa a ter uma compreensão comum, se pode também notar mudanças conceituais, a partir da interação.

No exemplo 1, primeiramente os alunos participaram de aula expositiva e assistiram a um vídeo. Posteriormente, eles foram indagados sobre o conteúdo trabalhado no vídeo e na exposição. O conceito trabalhado é putrefação $o^{1}$. No trecho do diálogo, dois alunos tentaram elaborar um texto sobre um vídeo a que assistiram, sem, no entanto, conseguir chegar a uma conclusão sobre o conceito.

Exemplo 1 - Significado de putrefação.

Pesquisadora: Você sabe o que é putrefação?

Aluno S: Isso, nós não sabemos.

Aluno R: É uma invenção?

\footnotetext{
${ }^{1}$ Putrefação se caracteriza pelo processo de apodrecimento de matérias orgânicas.
} 
Pesquisadora: Quando você deixa uma banana muito tempo para amadurecer, o que acontece com ela?

Aluno R: Fica podre, preta.

Pesquisadora: Isso, putrefação é quando a matéria orgânica apodrece. Quando você deixa muito tempo uma maçã fora da geladeira, o que acontece com ela, Aluno R?

Aluno R: Quando é resto de comida, apodrece. Fica preto.

Pesquisadora: O que é putrefação?

Aluno R: Apodrecimento do que a gente come.

Aluno S: É o resto de comida que apodrece, que vem da matéria orgânica.

Pode-se perceber que os alunos não estavam conseguindo constituir um novo conhecimento, já que já tinham assistido a um vídeo e a uma aula expositiva, e este parecia ainda distante da sua realidade, porquanto um deles ainda indaga: "É uma invenção?". No entanto, quando a pesquisadora argumenta o conteúdo de forma próxima à realidade deles, falando de frutas como banana, tornando-o próximo ao meio sociocultural dos aprendentes, logo, emergiram ZDP singulares para cada aluno, e eles conseguem formular um conceito que até então não conheciam.

Abordando as contribuições de Vygotsky, Silva (2014) discorre que o desenvolvimento potencial se estabelece através das vivências, em que o sujeito precisa da mediação e colaboração de pares mais experientes para constituir seus conhecimentos. Sendo assim, para que as ZDP venham a emergir, é necessário que haja mediação, que se define como a ação intermediada entre o sujeito o objeto.

\subsubsection{Protagonismo estudantil}

Denomina-se protagonismo estudantil quando os participantes conseguiram tomar decisões, fazer escolhas e conduzir de alguma maneira as atividades. Dessa forma, contribuíram para a aprendizagem dos colegas e da pesquisadora, saindo do papel de aluno receptor para aquele que participa e constrói seu processo de aprendizagem.

Foram encontradas facilitações para a emergência de ZDP, pelo fato de que através do protagonismo o aprendente conseguiu ir além do seu nível de desenvolvimento. Considera-se o aluno como sujeito ativo e participante do seu processo de aprendizagem, conseguindo vivenciar e ultrapassar situações, funções e papéis que no seu dia a dia não tinha a oportunidade de exercer.

Durante o desenvolvimento do projeto, enquanto os grupos produziam os vídeos e faziam o apanhado das fotos, entrevistas e todo o material coletado na aula de campo, o aluno $\mathrm{M}$ demonstrou habilidades com o desenho, e um dos colegas do grupo sugeriu a constituição de uma mascote para o grupo de alunos monitores. M logo se interessou, e rascunhou vários personagens, demonstrando também uma relação com o conteúdo de sustentabilidade, e autonomia no seu desenvolvimento.

Os personagens exibiam características de heróis, e tinham como principal objetivo o desenvolvimento da sustentabilidade. Através desse exemplo, pode-se perceber que houve aspectos de autonomia e protagonismo estudantil, haja vista que ele teve a iniciativa de fazer uma produção com a ajuda do colega, objetivando concretizar o que eles estavam desenvolvendo na teoria. Na Figura 2, a mascote selecionada.

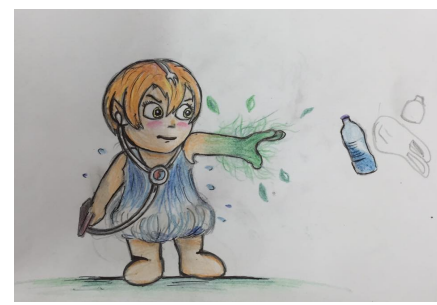

Figura 2 - Mascote escolhida.

Fonte: Dados da pesquisa. 
Destaca-se também outra situação que favoreceu o protagonismo dos alunos, em que eles decidiram qual personagem ia representar o grupo. Descentralizando o processo no qual só o professor decide e comanda, os aprendentes puderam também escolher, decidir e conduzir as atividades, trazendo o processo de ensino e aprendizagem para perto de sua realidade, corroborando mais uma vez as ideias de Vygotsky (1994), que considera a influência do meio cultural decisiva para que ocorra a aprendizagem. Nesse momento, também foi percebida a compreensão dos participantes em relação ao tema estudado.

Depois de escolhido o personagem, o grupo propôs uma votação, que foi vinculada ao Facebook, para escolha do nome da mascote que iria representar o grupo todos foram relacionados a identificação do personagem ao assunto estudado durante as formações, tais como Flora e Sustendyn.

Foram demonstradas através da análise dos resultados, as vivências que evidenciaram interações e conversações entre os aprendentes, mediadas pela utilização dos recursos digitais. Esse processo, aliado ao compartilhamento de conhecimentos, facilitou as emergências de ZDP. Os resultados foram relacionados a partir de categorias inter-relacionadas, que auxiliaram no entendimento da forma como emergem as ZDP, destacando a forma como se dá a aprendizagem quando mediada pelas tecnologias.

\section{CONSIDERAÇÕES FINAIS}

A trajetória trilhada até o momento revelou singularidades e características dos processos de ensino e aprendizagem, mediados pelas tecnologias digitais, buscando-se entender como ocorre a aprendizagem. A partir das vivências dos alunos, procurou-se relacionar essa práxis com base em questões teóricas.

A metodologia diversificada, envolvendo diferentes tipos de recursos, como tablets, aula de campo, visualização de vídeos, apresentação dos trabalhos para os colegas, produção de slides e vídeos, enquetes e essencialmente atividades em grupo, forneceram um contexto fomentador de ZDP. Os parâmetros identificadores de ZDP foram: espaços de diálogos entre o aprendente e pares e/ou alguém mais experiente; compreensão e/ou constituição de um novo conceito; compreensão conjunta; e mudanças conceituais e mediação, ou seja, através das ações intermediadas entre sujeito e objeto. A partir da análise e discussão dos resultados ficou bastante clara a potência transformadora do projeto, na dimensão política e social.

Um fator importante que poderá ser considerado em pesquisas futuras é a ampliação dos estudos para alunos que tenham acesso mais restrito às tecnologias, que não tenham participado do curso de formação, verificando-se como eles reagem em meio às possibilidades oferecidas por tais recursos. Espera-se, portanto, que este estudo possa despertar novos anseios e inquietações, trazendo contribuições e inovações para esse contexto pedagógico aliado ao uso das tecnologias, de grande interesse no momento atual.

\section{REFERÊNCIAS}

BOGDAN, R. C.; BIKLEN, S. K. Investigação qualitativa em educação. Porto: Porto Editora, 1994.

BONILLA, Maria Helena Silveira. A presença da cultura digital no GT Educação e Comunicação da Anped. Revista Teias, v. 13, n. 30, p. 71-93, set./dez. 2012.

CASTELLS, M. A sociedade em rede: a era da informação: economia, sociedade e cultura. São Paulo: Paz e Terra, 1999. 
COLAÇO, V. F. R. Interações em sala de aula: um estudo da atividade discursiva de crianças em séries iniciais. 2001. Tese (Doutorado em Educação) - Programa de PósGraduação em Educação, Universidade Federal do Rio Grande do Sul, Porto Alegre, 2001.

Processos interacionais e a construção de conhecimento e subjetividade de crianças. Psicologia: Reflexão e Crítica, v. 17, n. 3, p. 333-340, 2004.

DAVID, P. B. Interações contingentes em ambientes virtuais de aprendizagem. 2010. 226 f. Tese (Doutorado em Educação) - Faculdade de Educação, Universidade Federal do Ceará, Fortaleza, 2010.

LUCKIN, R. et al. Using mobile technology to create flexible learning contexts. Journal of Interactive Media in Education, v. 22, 2005.

MARTINS, E. R. et al. Tecnologias móveis em contexto educativo: uma revisão sistemática da literatura. Revista Novas Tecnologias na Educação, v. 16, n. 1, 2018.

MEIRA, L. Análise microgenética e videografia: ferramentas de pesquisa em psicologia cognitiva. Temas em Psicologia, v. 2, n. 3, p. 59-71, 1994.

MEIRA, L.; LERMAN, S. Zones of Proximal Development as fields for communication and dialogue. In: LIGHTFOOT, C. M. C. D.; LYRA, P. (Org.). Challenges and strategies for studying human development in cultural contexts. Roma: Firera Publishing, 2009. p. 199-220.

MEIRA, L.; SPINILLO, A. G. Psicologia cognitiva: cultura, desenvolvimento e aprendizagem. Recife: Universitária, 2006.

NARDI, Bonnie A. Activity theory and human-computer interaction. In: (Ed.).

Context and consciousness: activity theory and human-computer interaction. Massachusetts: MIT, 1996. p. 7-16.

OLIVEIRA, S. Vygotsky e a ZDP. Folhetim de Aprendizagem, Lavras, n. 28, 2014. Disponível em: $<$ http://www.nadp.ufla.br/2013/wp-content/uploads/2014/02/Folhetim28-Vygotsky-e-a-ZDP.pdf>. Acesso em: 28 jun. 2015.

RESTA, Paul; LAFERRIÈRE, Thérèse. Technology in support of collaborative learning. Educational Psychology Review, v. 19, n. 1, p. 65-83, 2007.

SILVA, M. A. Trabalho colaborativo em rede no projeto Um Computador por Aluno (UCA): conhecimentos e práticas docentes. 2014. Tese (Doutorado em Educação) - Faculdade de Educação, Universidade Federal do Ceará, Fortaleza, 2014.

VYGOTSKY, L. S. A formação social da mente. São Paulo: Martins Fontes, 1994.

WERTSCH, James V. The mediation of mental life: L. S. Vygotsky and M. M. Bakhtin. In: MERTZ, E.; PARMENTIER, R. J. (Org.). Semiotic mediation: sociocultural and psychological perspectives. Orlando: Academic Press, 1985. p. 49-71. 